\title{
Overexpression of snapdragon Delila (Del) gene in tobacco enhances anthocyanin accumulation and abiotic stress tolerance
}

\author{
Aung Htay Naing ${ }^{1}$, Kyeung II Park², Trinh Ngoc Ai ${ }^{1}$, Mi Young Chung ${ }^{3}$, Jeung Sul Han'1, Young-Wha Kang ${ }^{1}$,
} Ki Byung Lim ${ }^{1}$ and Chang Kil Kim*

\begin{abstract}
Background: Rosea1 (Ros1) and Delila (Del) co-expression controls anthocyanin accumulation in snapdragon flowers, while their overexpression in tomato strongly induces anthocyanin accumulation. However, little data exist on how Del expression alone influences anthocyanin accumulation.

Results: In tobacco (Nicotiana tabacum 'Xanthi'), Del expression enhanced leaf and flower anthocyanin production through regulating NtCHS, NtCHI, NtF3H, NtDFR, and NtANS transcript levels. Transgenic lines displayed different anthocyanin colors (e.g., pale red: $T_{0}-P$, red: $T_{0}-R$, and strong red: $T_{0}-S$ ), resulting from varying levels of biosynthetic gene transcripts. Under salt stress, the $T_{2}$ generation had higher total polyphenol content, radical (DPPH, ABTS) scavenging activities, antioxidant-related gene expression, as well as overall greater salt and drought tolerance than wild type (WT).

Conclusion: We propose that Del overexpression elevates transcript levels of anthocyanin biosynthetic and antioxidantrelated genes, leading to enhanced anthocyanin production and antioxidant activity. The resultant increase of anthocyanin and antioxidant activity improves abiotic stress tolerance.
\end{abstract}

Keywords: Antioxidant activity, bHLH protein, Drought stress, Salt stress, Transgenic tobacco

\section{Background}

Anthocyanins are plant pigments produced via a dedicated biosynthetic pathway in flowers, fruit, leaves, and stems. Ornamental plants with novel colors and coloration patterns are of great commercial value in the floricultural industry, as they are among the most important aesthetic characters for consumers. Plant breeders have developed various flower colors using natural mutants or interspecific hybridization. However, current breeding techniques cannot create particular flower colors in some plant species due to hybridization barriers. Genetic engineering offers an alternative approach that has successfully developed these desired flower colors in common floricultural plants, including roses and carnations [1].

\footnotetext{
* Correspondence: ckkim@knu.ac.kr

${ }^{1}$ Department of Horticultural Science, Kyungpook National University, Daegu

4165122, South Korea

Full list of author information is available at the end of the article
}

The transgenic expression of anthocyanin regulatory transcription factors from ornamental plants led to anthocyanin production in other plants [1]. For example, anthocyanin production was enhanced in tomato with the co-expression of snapdragon (Antirrhinum majus)-derived bHLH transcription factor Delila $(D e l)$ and the MYB transcription factor Rosea1 (Ros1) [2, 3]. Furthermore, AtMYB12, Del, and Ros1 overexpression enhanced anthocyanin biosynthetic gene expression, as well as activating primary metabolism [4]. However, only a single study to date has examined the effect of of $\mathrm{Del}$ alone on anthocyanin production (in tobacco) [5]. Thus, more data are necessary to fully understand of the involvement of this gene in anthocyanin-linked flower pigmentation.

Ongoing global warming scenarios in climate models have predicted that drought severity and soil salinity will steadily increase (IPCC 2007). Both are major abiotic stressors; drought severely arrests plant growth and development through a reduction in cell division and 
expansion rates, leaf size, stem elongation, root proliferation, and water use efficiency [6]. These changes eventually cause crop biomass a reduction. Similarly, salinity alters many physiological and biochemical processes that disturb normal plant growth and development [7], thus adversely affecting crop productivity and quality [8]. Abiotic stress can increase reactive oxygen species (ROS), leading to cell damage from oxidative stress [9]. Plants cope with the damage through generating antioxidant enzymes, such as superoxide dismutase (SOD), catalase (CAT), peroxidase (POD), and ascorbate peroxidase (APX).

Previous studies have reported that plants with high anthocyanin content also possess high antioxidant capacity. Moreover, these plants exhibit resistance against a variety of abiotic and biotic stressors, including salinity and drought, as well as microbial and fungal attacks $[10,11]$. This increased general tolerance is attributable to antioxidants scavenging ROS that impede plant growth (e.g., hydrogen peroxide, singlet oxygen, superoxide radicals [12, 13]. Thus, in addition to its role in plant coloration, anthocyanins are important antioxidants responsible for protection from major stressors. In support of this function, a recent study suggested that high anthocyanin content in transgenic tobacco enables the plants to tolerate relatively low ROS accumulation under chilling stress [14]. Similarly, antioxidants were shown to be important in protecting plants against salt-stress-induced oxidative damage [15]. Furthermore, flavonols are compounds with high antioxidant activity, and the upregulation of their biosynthesis increased protection against UV radiation in Ligustrum vulgare plants [16]. Potato plants overexpressing transcription factor $I b M Y B 1$ exhibited enhanced anthocyanin production and improved salinity tolerance [17]. Anthocyanin biosynthetic genes PAL and CHS are proposed as candidates for molecular breeding to increase crop resistance to wounding and salt stress [18]. Finally, Fini et al. [19] and Nakabayashi et al. [20] showed that improved abiotic stress tolerance under enhanced flavonoid accumulation is linked to greater ROS scavenging ability. However, these previous works did not directly investigate the association between plant anthocyanin content and abiotic stress tolerance. Hence, our research aims to address this gap.

In this study, we generated transgenic tobacco expressing snapdragon-derived $D e l$, and then investigated its role in anthocyanin production using phenotypic and molecular characterization. In addition, we examined stress-induced antioxidant activity and related gene expression to understand how increased anthocyanin content from Del overexpression affected salt and drought tolerance.

\section{Results}

The $\mathrm{T}_{0}$ transgenic phenotypes displayed stem and leaf colors corresponding to differing anthocyanin accumulation levels: pale red $\left(\mathrm{T}_{0}-\mathrm{P}\right)$, red $\left(\mathrm{T}_{0}-\mathrm{R}\right)$, and strong red $\left(\mathrm{T}_{0}-\mathrm{S}\right)$ (Fig. 1a). Upon transferal to a greenhouse alongside wild type (WT), anthocyanin accumulation was maintained in transgenic lines and obvious between-line phenotypic variation was observed (Fig. 1b).

Homozygous lines in the $\mathrm{T}_{2}$ generation were verified using Mendel's segregation laws (data not shown). Next, $T_{2}-P, T_{2}-R$, and $T_{2}-S$ plants were selected for analysis of anthocyanin content and molecular characterization.

Leaf anthocyanin content was highest in $\mathrm{T}_{2}-\mathrm{S}$ plants, followed by $T_{2}-R, T_{2}-P$, and finally WT (Fig. 2a). Anthocyanin content was also associated with the color of each extract (Fig. 2b).

The results of RT-PCR indicated that all investigated anthocyanin biosynthetic genes (NtCHS, NtCHI, NtF3H, $N t D F R$, and $N t A N S$ ) were expressed in the leaves of transgenic lines, while NtDFR and NtANS were not expressed in WT leaves (Fig. 3a). Thus, Del overexpression appears to regulate all major genes involved in the anthocyanin biosynthetic pathway. Moreover, low anthocyanin content in WT corresponds to the lack of NtDFR and NtANS expression.

We further investigated gene transcript levels using qRT-PCR to understand why anthocyanin accumulation differed across transgenic lines, even though they all expressed anthocyanin biosynthetic genes post-Del overexpression. Gene expression in the transgenic lines was correlated with anthocyanin accumulation: the highest transcript levels were found in $\mathrm{T}_{2}-\mathrm{S}$, followed by $\mathrm{T}_{2}-\mathrm{R}$, $\mathrm{T}_{2}-\mathrm{P}$, and finally WT (Fig. 3b-f). Notably, DFR and ANS expression was significantly higher in $T_{2}-R$ than in $T_{2}-P$. Additionally, $\mathrm{T}_{2}-\mathrm{S}$ and $\mathrm{T}_{2}-\mathrm{R}$ had similar DFR transcript levels, but the former exhibited significantly higher expression for all other genes.

Transgenic flowers were redder than the pale pink of WT, ranging from dark pink $\left(\mathrm{T}_{2}-\mathrm{S}\right)$, orange pink $\left(\mathrm{T}_{2}-\mathrm{R}\right)$, to pink ( $\left.\mathrm{T}_{2}-\mathrm{P}\right)$ (Fig. 4a). We next used RT-PCR to examine how flower color is influenced by genes controlling the anthocyanin biosynthetic pathway (NtCHS, NtCHI, $N t F 3 H, N t D F R$, and NtANS). All analyzed genes were expressed in both transgenic and WT flowers, differing from leaf tissue expression patterns with no WT NtDFR and NtANS expression. However, as observed for leaves, transcript levels of all biosynthetic genes were highest in $\mathrm{T}_{2}$-S flowers, followed by $\mathrm{T}_{2}-\mathrm{R}, \mathrm{T}_{2}-\mathrm{P}$, and lastly, WT flowers (Fig. 4b-f).

\section{Environmental stress experiments \\ Antioxidant activity in transgenic lines and WT before stress treatment}

To evaluate the association between anthocyanin content and antioxidant activity, we analyzed total radicalscavenging activity (2,20-azinobis [3-ethylbenzothiazoline-6-sulfonic acid] diammonium salt: ABTS and 1,1- 

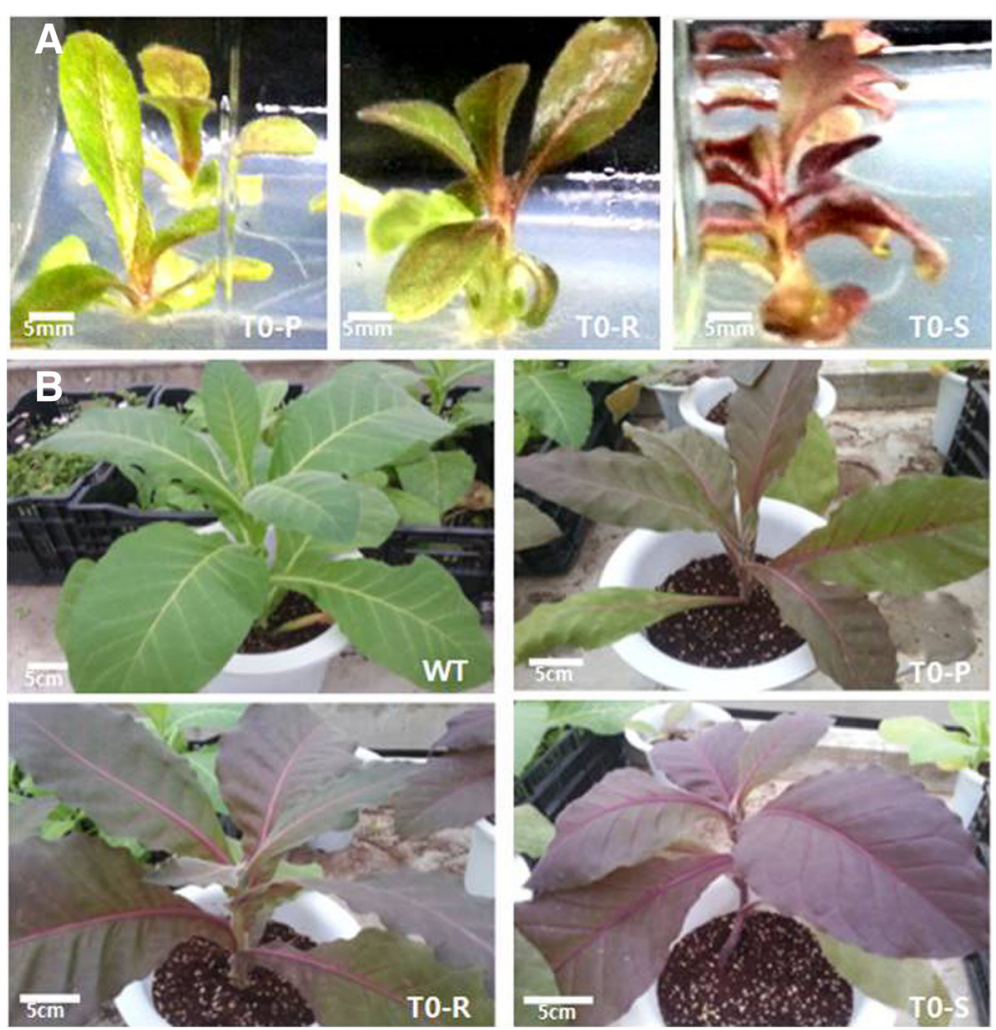

Fig. 1 Comparing anthocyanin-content phenotypes across (a) three independent Del-overexpressing transgenic lines (in vitro stage) and across (b) WT and transgenic lines (in greenhouse conditions). All lines exhibited different phenotypes. $T_{0}-P_{1}, T_{0}-R$, and $T_{0}-S$ refer to pale red, red, and strong red transgenic plants in the $T_{0}$ generation, respectively

diphenyl-2-picrylhydrazyl: DPPH) and total polyphenol content of leaf extracts from non-treated four-week-old $\mathrm{T}_{2}-\mathrm{P}, \mathrm{T}_{2}-\mathrm{R}, \mathrm{T}_{2}-\mathrm{S}$, and WT plants. Antioxidant activity and total polyphenol content were highest in $\mathrm{T}_{2}-\mathrm{S}$ and lowest in WT, with $\mathrm{T}_{2}-\mathrm{R}$ and $\mathrm{T}_{2}-\mathrm{P}$ in between (Fig. 5). This pattern indicated that higher anthocyanin content in transgenic lines leads to higher antioxidant activity.

\section{Salt stress tolerance}

The effect of salt stress on both transgenic and WT plant growth was not obvious following irrigation with $50 \mathrm{mM}$ $\mathrm{NaCl}$ (data not shown). However, increasing $\mathrm{NaCl}$ concentrations to $100 \mathrm{mM}$ and $150 \mathrm{mM}$ caused clear leaf curling and a decrease in shoot length. Under these conditions, WT leaves were succulent and brittle, while transgenic leaves appeared more normal (Fig. 6a). When $\mathrm{NaCl}$ concentration was increased to $200 \mathrm{mM}$ and $250 \mathrm{mM}$, all plants exhibited obvious stunted growth, including reduced height. Under these conditions, $T_{2}-P$ and $T_{2}-R$ leaves drooped, while $\mathrm{T}_{2}-\mathrm{S}$ plants appeared more normal. A final increase of $\mathrm{NaCl}$ concentration to $300 \mathrm{mM}$ severely affected all plant growth in the following order: $\mathrm{WT}>\mathrm{T}_{2}-\mathrm{P}>\mathrm{T}_{2}-\mathrm{R}>\mathrm{T}_{2}-\mathrm{S}$, as measured by impairments to plant height and fresh weight (Fig. $6 \mathrm{~b}$ and $\mathrm{c}$ ).

\section{Antioxidant activity in transgenic lines and WT after salt stress treatment}

Following salt stress, antioxidant activity (ABTS and DPPH) and total polyphenol content of transgenic and WT plants were re-measured. Salt-stressed plants exhibited similar patterns in antioxidant activity and total polyphenol content as non-treated plants: highest in $\mathrm{T}_{2}$-S, intermediate in $\mathrm{T}_{2}-\mathrm{R}$ and $\mathrm{T}_{2}-\mathrm{P}$, lowest in WT (Fig. 7a-c). However, absolute levels of both variables were distinctly lower in salt-stressed plants than in non-treated plants. In particular, differences between salt-stressed and non-treated WT plants were greater than those seen for the transgenic lines (Fig. 7a-c).

\section{Measurement of ionic compounds after salt-stress treatment}

The order of $\mathrm{Na}^{+}$uptake was as follows: WT $>\mathrm{T}_{2}-\mathrm{P}>$ $\mathrm{T}_{2}-\mathrm{R}>\mathrm{T}_{2}$-S (Fig. 8). Following salt-stress treatment, percentage accumulation of $\mathrm{K}^{+}, \mathrm{Mg}^{2+}$, and $\mathrm{Ca}^{2+}$ decreased in leaves, leading to the following order of ion content: $\mathrm{WT}<\mathrm{T}_{2}-\mathrm{P}<\mathrm{T}_{2}-\mathrm{R}<\mathrm{T}_{2}$-S (Fig. 8).

\section{Effect of salt-stress treatment on gene expression}

Transcript levels of NtSOD, NtCAT, NtPOX, and NtOsmotin were lowest in WT, then increased in transgenic 


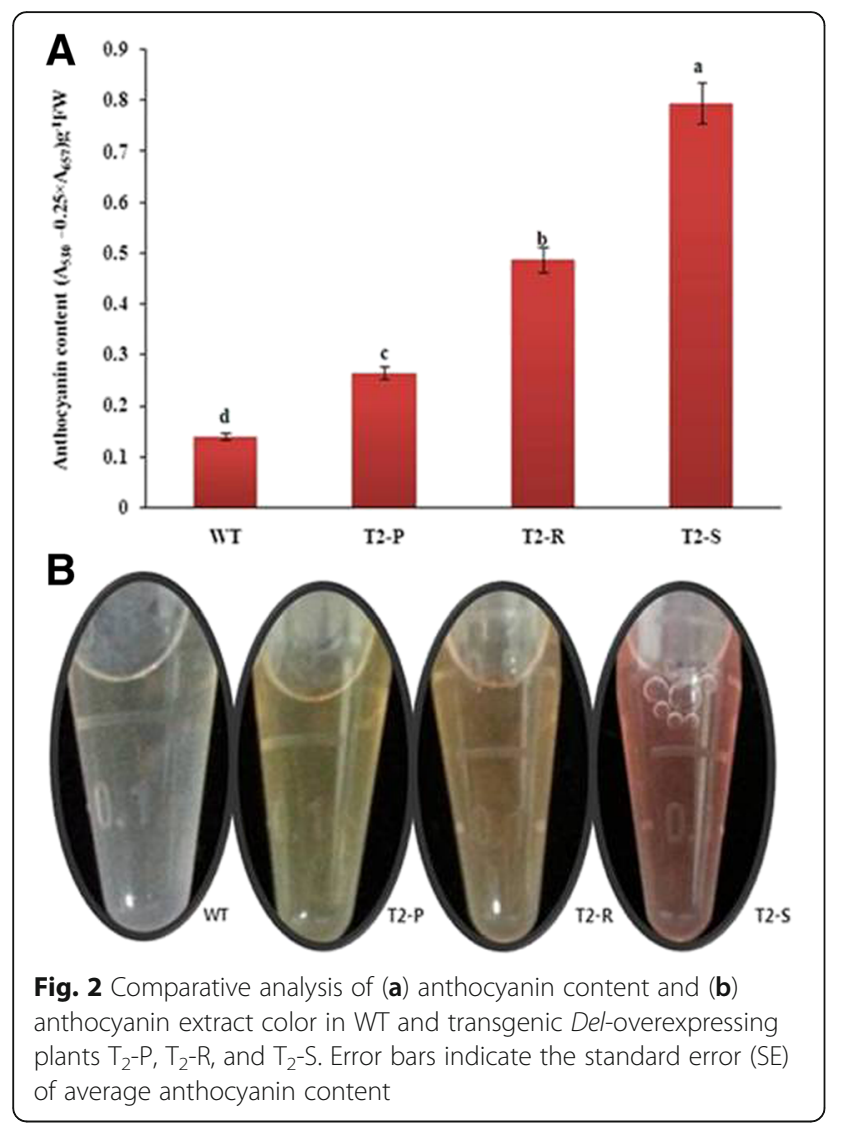

lines as follows: $T_{2}-P<T_{2}-R<T_{2}-S$ (Fig. 9). Low gene expression in WT would lead to decreased production of antioxidant enzymes that provide salt-stress tolerance (i.e., SOD, CAT, and POX, and proline). Thus, this result supports the hypothesis that the higher salt-stress tolerance in transgenic lines depends on their antioxidant content.

\section{Drought stress tolerance}

Under well-watered conditions, leaf size and plant height did not obviously differ between WT and transgenic plants. However, following 10 days of water deprivation, almost all WT plant leaves appeared wilted, whereas in transgenic plants, only lower leaves were wilted, while upper leaves remained green and fully expanded (data not shown). Thus, we evaluated physiological parameters linked to drought-stress tolerance, such as leaf stomatal density, relative water content (RWC), and MDA content.

In general, drought stress tolerance depends on transpiration rate, which is affected by stomatal density. Stomatal density was in the order of $\mathrm{T}_{2}-\mathrm{S}<\mathrm{T}_{2}-\mathrm{R}<\mathrm{T}_{2}-\mathrm{P}$ $<\mathrm{WT}$, while RWC was $40 \%, 55 \%, 70 \%$, and $80 \% \mathrm{WT}$, $\mathrm{T}_{2}-\mathrm{P}, \mathrm{T}_{2}-\mathrm{R}$, and $\mathrm{T}_{2}-\mathrm{S}$ plants, respectively (Fig. 10a). Consistent with these results, the water holding capacity during 10 days of drought stress was highest in $\mathrm{T}_{2}$-S, followed by $\mathrm{T}_{2}-\mathrm{R}, \mathrm{T}_{2}-\mathrm{P}$, and finally WT (Fig. 10b). High RWC in $\mathrm{T}_{2}-\mathrm{S}$ plants could be partially attributed to low stomatal density. Next, MDA content was lowest in $\mathrm{T}_{2^{-}}$ $S$, then in $T_{2}-R, T_{2}-P$, and lastly, WT (Fig. 10c), suggesting that reduced MDA from anthocyanin accumulation led to improved drought stress tolerance in the transgenic lines.

After 21 days of water deprivation, all WT and $\mathrm{T}_{2}-\mathrm{P}$ leaves turned yellow, with greater mortality in WT plants. Upper leaves of $T_{2}-R$ and $T_{2}-S$ plants displayed severe wilting only. After three days of re-watering, no WT plants recovered from drought stress, but new shoots from lower stem nodes were visible in $T_{2}-\mathrm{P}$

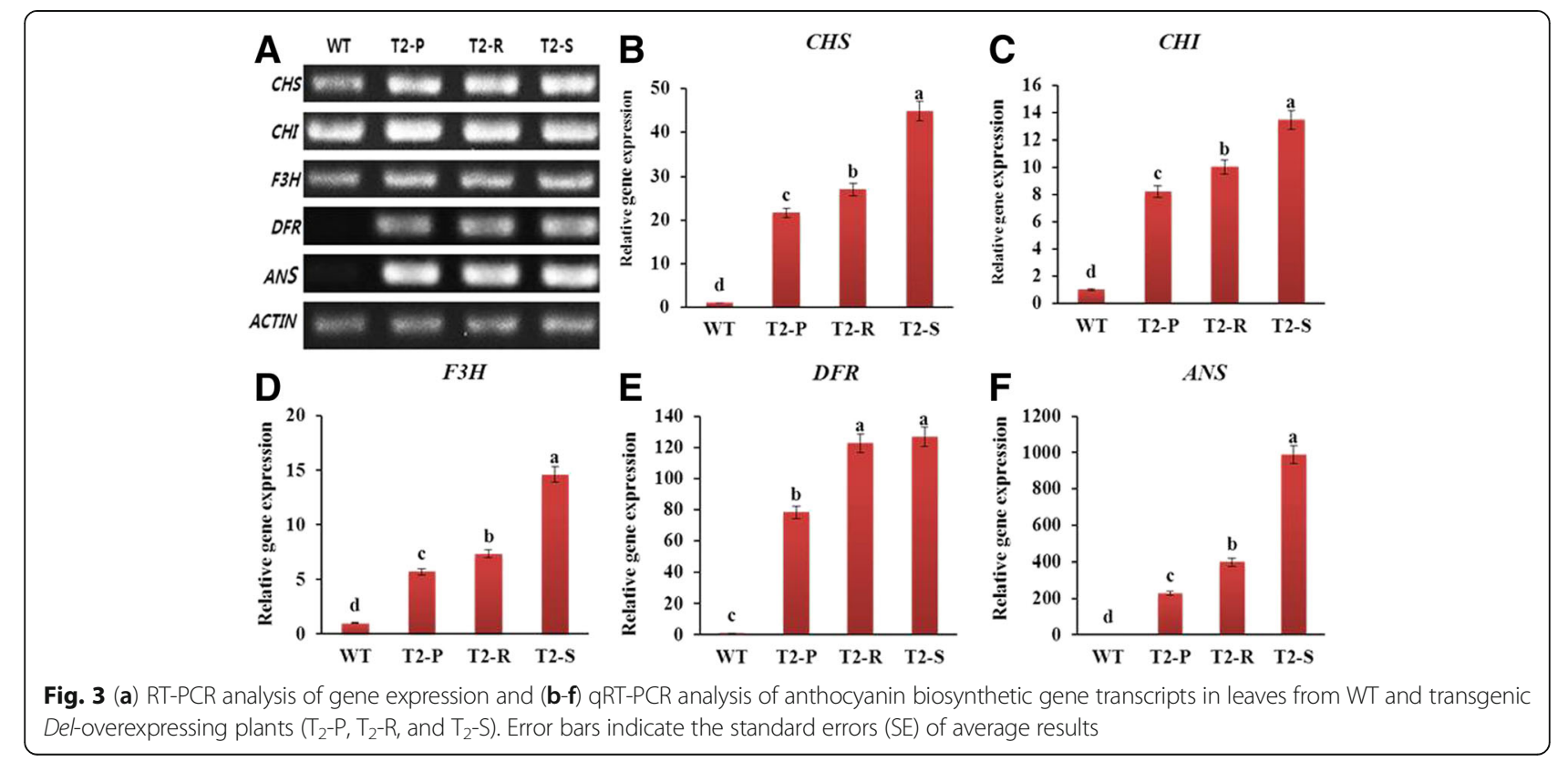



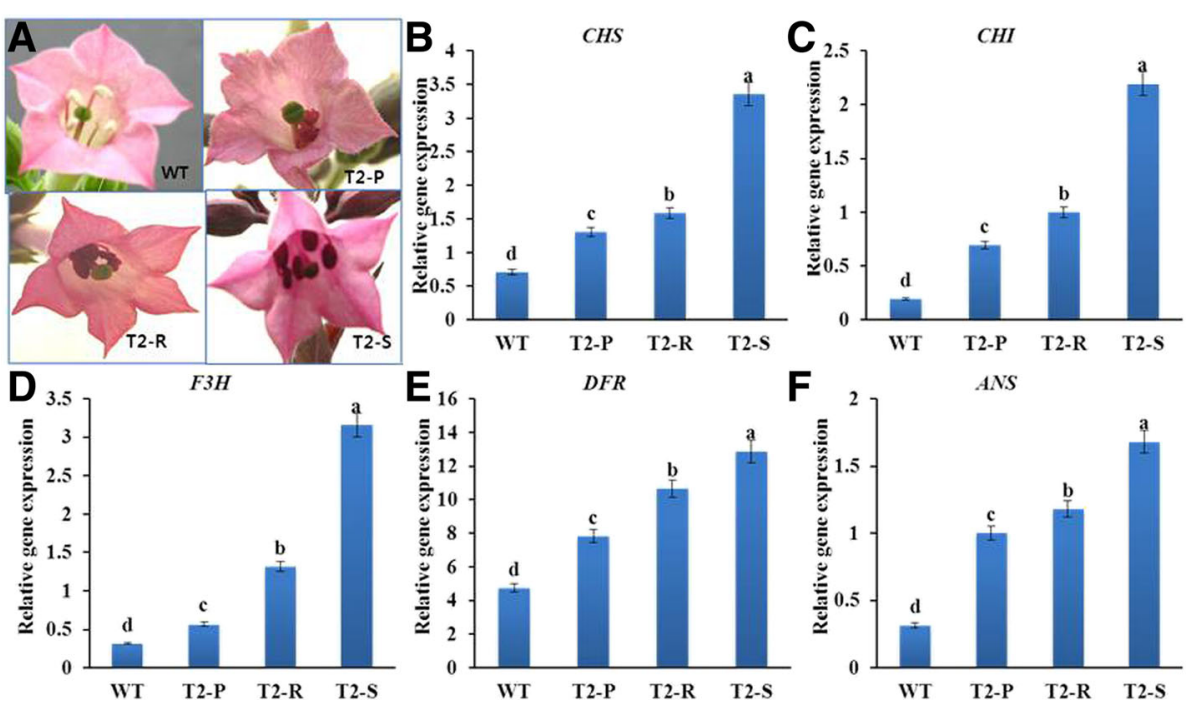

Fig. 4 Comparison of differences in flower phenotype (a) and (b-f) qRT-PCR analysis of anthocyanin biosynthetic gene transcripts in flowers from $W T$ and transgenic Del-overexpressing plants $\left(T_{2}-P, T_{2}-R\right.$, and $\left.T_{2}-S\right)$. Error bars indicate the standard errors (SE) of average results

plants (Fig. 11). Furthermore, $\mathrm{T}_{2}-\mathrm{S}$ and $\mathrm{T}_{2}-\mathrm{R}$ plants recovered well from drought stress, with their upper leaves comparable to those observed on well-watered plants (Fig. 11).

\section{Discussion}

Although previous studies have examined the overexpression of regulatory genes affecting anthocyanins in various plant species, only a few reports have investigated the effect of Del. Thus, in this study, we focused on the involvement of $\mathrm{Del}$ in anthocyanin accumulation. In contrast to Mooney et al. [5], we found enhanced anthocyanin accumulation in vegetative tissue of transgenic Del-overexpressing tobacco. However, both the previous work and our current study observed enhanced anthocyanins in floral tissues (i.e., petal, corolla, and stamen). The between-study difference in anthocyanin accumulation of vegetative tissue is likely due to tobacco cultivar choice ('Samsun' in Mooney et al. [5]). Additionally, Mooney et al. [5] demonstrated that NtCHS and $N t D F R$ absence explained the lack of anthocyanin accumulation in vegetative tissue. Our data support this conclusion, as we also did not detect NtDFR expression in the tobacco cultivar 'Xanthi' (WT) used here. Huang et al. [21] reported that $L c$ overexpression in tobacco upregulated NtDFR transcript levels, leading to purple pigmentation in young leaves at low temperatures, whereas in WT, NtDFR was not expressed and the pigmentation was absent. In this study, WT did not express either NtDFR or NtANS, while its expression of NtCHS, $\mathrm{NtCHI}$, and $\mathrm{NtF} 3 \mathrm{H}$ were relatively low. Thus, our results indicate that $\mathrm{Del}$ can regulate all biosynthetic genes and increase their expression levels. In addition, variation in anthocyanin accumulation among transgenic lines can be attributed to their differing biosynthetic gene transcript levels. However, some genes appear to play more important roles in enhancing anthocyanin production. As evidence, NtANS and NtDFR transcripts differed noticeably between $\mathrm{T}_{2}-\mathrm{R}$ and $\mathrm{T}_{2}-\mathrm{P}$ plants, whereas $N t C H S$, $N t C H I$, and $N t F 3 H$ transcripts did not. Moreover, $N t D F R$ transcripts were nearly identical between $\mathrm{T}_{2}-\mathrm{R}$ and $\mathrm{T}_{2}-\mathrm{S}$ plants, while higher $N t C H S, N t F 3 H$, and $N t A N S$ transcript levels were observed in the latter line. Collectively, these results indicate that $N t D F R$ and $N t A N S$ are critical in anthocyanin production of $\mathrm{T}_{2}-\mathrm{R}$ and $\mathrm{T}_{2}-\mathrm{P}$, while $N t C H S, N t F 3 H$, and NtANS are more relevant in $\mathrm{T}_{2}-\mathrm{R}$ and $\mathrm{T}_{2}-\mathrm{S}$. Thus, although all biosynthetic genes are responsible for anthocyanin accumulation, NtANS was most crucial in transgenic lines. This finding distinguishes our study from previous reports [5] that did not investigate the role of biosynthetic genes in controlling differing anthocyanin accumulation levels. In another study [21], NtDFR absence was thought to be the major reason for anthocyanin biosynthesis inactivation in WT leaves, although NtANS transcript levels were distinctly higher than those of NtDFR in their transgenic lines. Nakatsuka et al. [22] also generated transgenic tobacco expressing 35S:GhDFR cloned from gerbera, but did not describe anthocyanin production in vegetative tissue. Two studies that did examine anthocyanins in vegetative tissues found VlmybA2 or B-peru + mPAP1 overexpression in tobacco to enhance anthocyanin accumulation in those plant parts [23, 24], but neither study investigated the role of biosynthetic genes in anthocyanin production. 


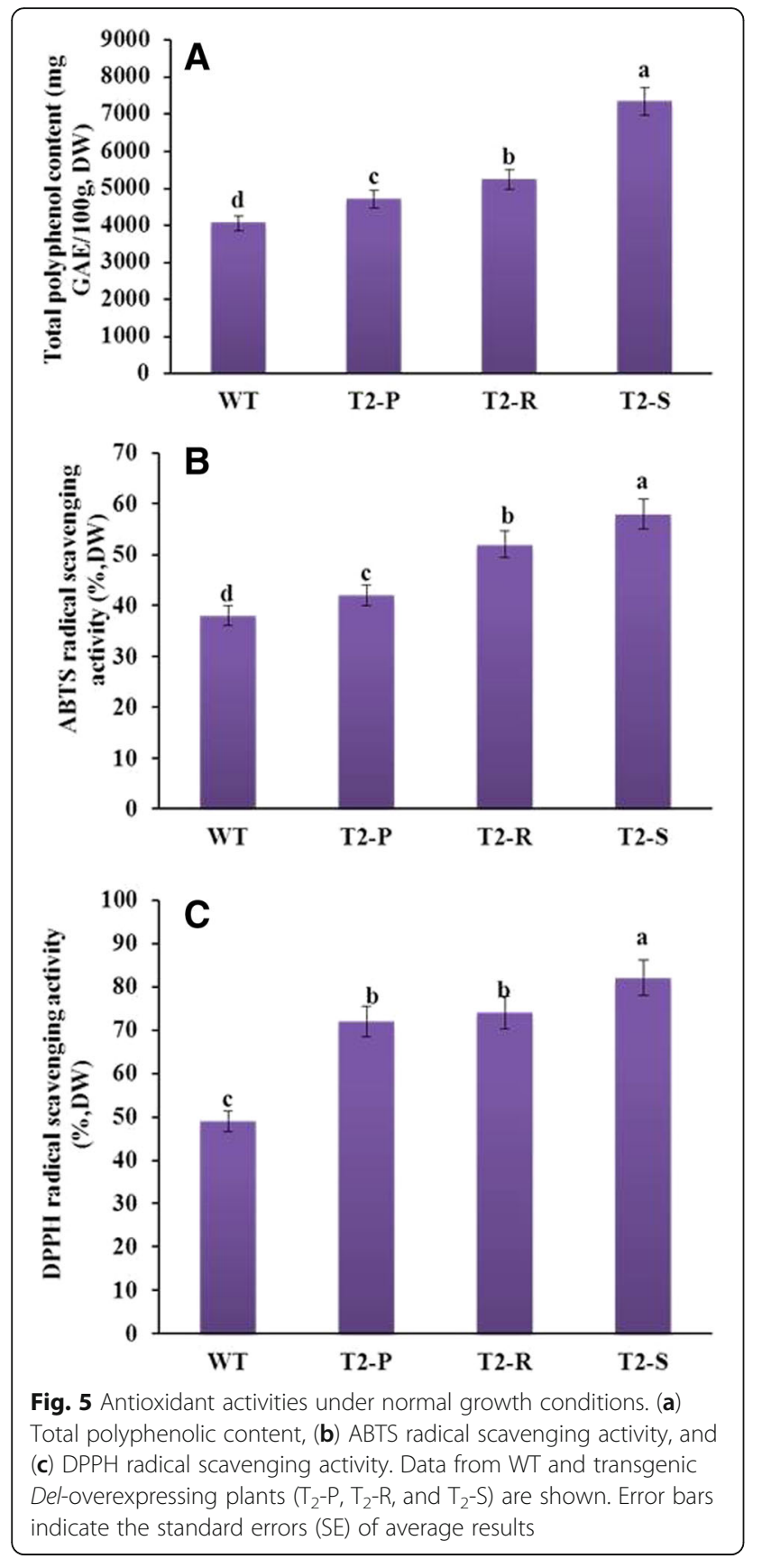

In contrast to their expression in vegetative tissue, all anthocyanin biosynthetic genes were expressed in the pink WT flowers. Similarly, although NtDFR expression was absent in in the vegetative tissue of cultivar 'Samsam', it was detected in the light pink flowers [5]. Here, transgenic and WT flower colors mirrored vegetative tissue colors, with pigmentation increasing in the order of $\mathrm{T}_{2}-\mathrm{S}>\mathrm{T}_{2}-\mathrm{R}>\mathrm{T}_{2}-\mathrm{P}>\mathrm{WT}$. The qRT-PCR results indicate that these pigmentation differences are linked to variation in biosynthetic gene transcript levels, as the latter influences anthocyanin accumulation. Therefore, $\mathrm{NtCHI}$,
$N t D F R$, and NtANS are probably more critical for flower color differences in 'Samsam' due to their higher transcript levels. These results confirm the findings of Mooney et al. [5], who reported that Del-mediated upregulation of NtDFR expression in tobacco flowers enhanced pigmentation. In addition, Han et al. [25] also showed that inhibition of $N t C H I$ and $N t D F R$ expression in tobacco flowers decreased anthocyanins.

Through the overexpression of foreign biosynthetic and regulatory genes, Geekiyanage et al. [23] and Nakatsuka et al. [22] successfully modified tobacco flower color. However, they did not investigate how those transformed genes regulated native biosynthetic genes, nor did they examine how the biosynthetic genes influenced anthocyanin production. A similar study [24] also enhanced anthocyanin production in the same cultivar, but did not examine flower color patterns. Additionally, pigmentation patterns in young leaves of three $L c$-expressing transgenic lines were investigated via examining anthocyanin biosynthetic gene transcript levels [21], but flower pigmentation patterns remained unexamined. Finally, a report demonstrating four new flower phenotypes from four independent, 35S-Tag1- $R$ transgenic lines did not evaluate those phenotypes with molecular characterization. Overall, $\mathrm{Del}$ overexpression in tobacco upregulates all anthocyanin biosynthetic genes, significantly increasing anthocyanin accumulation in vegetative and flower tissues. Thus, differences in anthocyanin accumulation across transgenic tobacco lines overexpressing $\mathrm{Del}$ are probably due to variation in anthocyanin biosynthetic gene transcript levels.

Environmental stresses that cause ROS generation are major threats affecting plant growth and yield. Owing to the threat of global climate change, plant scientists are increasingly interested in how plants sustain their yield under environmental stresses. According to the studies to date, when plants are exposed to environmental stress conditions, anthocyanin serves as an antioxidant enzyme and increases ROS scavenging activity to prevent plant damage [21, 26]. Oh et al. [27] suggested that enhanced anthocyanin content significantly increases Arabidopsis survival under salt stress. Similarly, anthocyanin increase confers heightened ROS scavenging activity in Melissa officinalis leaves [28]. Several other studies have also revealed that overexpression of anthocyanin regulatory gene IbMYB1 in potato [17] and anthocyanin biosynthetic gene $C H S$ in tobacco [29] enhances anthocyanin production and salt stress tolerance. Additionally, $M Y B$ overexpression in Arabidopsis plants causes anthocyanin over-accumulation, an outcome directly associated with oxidative- and drought-stress tolerance [20]. Moreover, overexpression of Scutellaria baicalensis R2R3-MYB genes (SbMYB2, SbMYB7, SbMYB8) regulates anthocyanin biosynthesis and improves abiotic stress tolerance in 

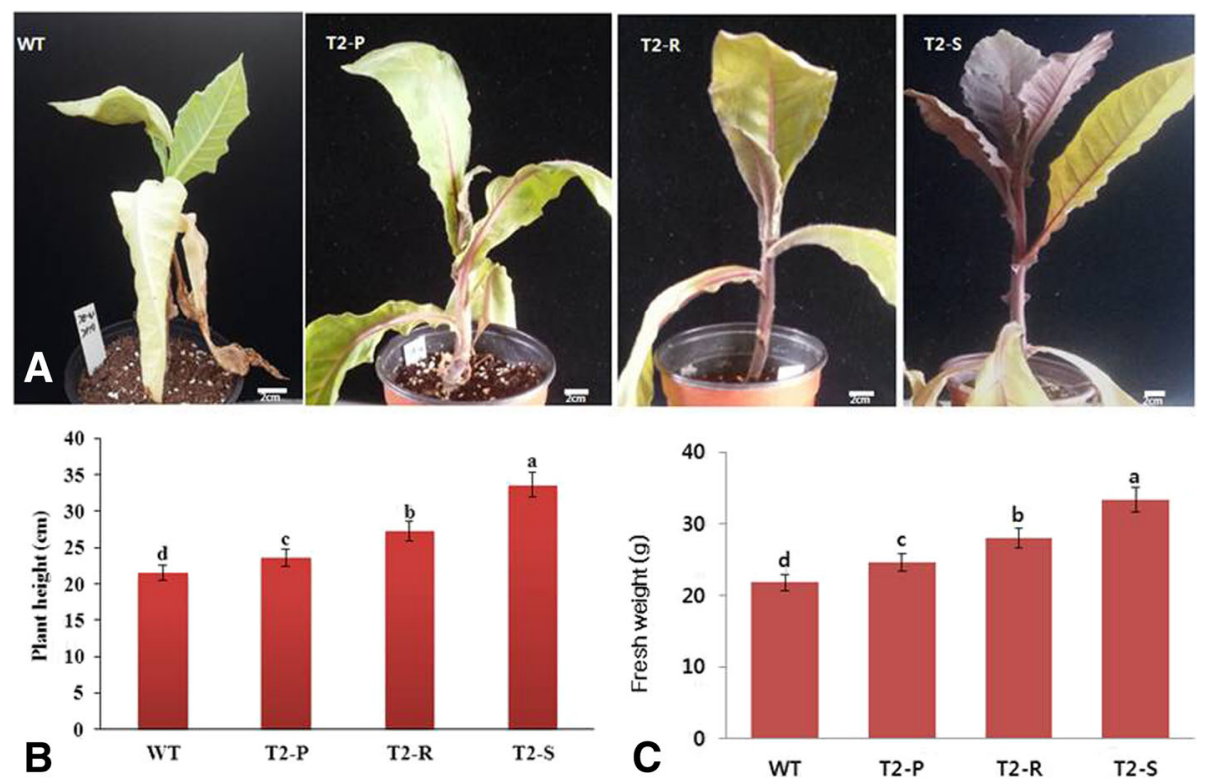

Fig. 6 Comparisons of post-salt-stress (a) phenotypes, as well as (b, c) plant height and fresh weight in WT and transgenic Del-overexpressing plants $\left(T_{2}-P, T_{2}-R\right.$, and $\left.T_{2}-S\right)$. Error bars indicate the standard errors (SE) of average results

tobacco [30, 31]. Likewise, expression of a grape bHLH transcription factor gene (VvbHLH1) increases flavonoid accumulation, leading to enhanced salt and drought tolerance in transgenic Arabidopsis [32]. Although Del overexpression in tobacco and tomato enhances anthocyanin production $[3,33]$, only one study before this current report investigated the influence of Del on salt and drought stress tolerance (in transgenic Arabidopsis) [34]. Unlike our study, however, Wang et al. [34] did not find a link between $\mathrm{Del}$ overexpression and anthocyanin accumulation in transgenic Arabidopsis. Further, they did not document any correlation between anthocyanin content and degree of stress tolerance.

Depending on anthocyanin accumulation levels, ABTS and DPPH radical scavenging activities and total polyphenol content varied across transgenic lines, but were lowest in WT. This result indicates that high anthocyanin accumulation is likely to be associated with better ROS scavenging activity (antioxidant activities), supporting the findings of Lim et al. [35]. These authors also reported that RsMYB1 overexpression in Arabidopsis greatly enhances anthocyanin production and improves antioxidant activity over WT, but they did not examine antioxidant activity in relation to varying amounts of anthocyanin accumulation.

Salt-stress treatments inhibited plant growth, lowered polyphenolic contents, and dampened antioxidant activities in every line. This outcome may be due to phenol and antioxidant consumption by plants to defend against salinity-induced oxidative stress. Throughout the stress treatment, stress tolerance was highest in $\mathrm{T}_{2}-\mathrm{S}$, followed by $\mathrm{T}_{2}-\mathrm{R}, \mathrm{T}_{2}-\mathrm{P}$, and lastly, WT. This variation in stress tolerance seems due to inter-line variation in phenol content and antioxidant activity. As currently understood, high antioxidant activity is necessary to neutralize salt-stress-induced ROS, thereby preventing oxidative damage to proteins, lipids, and nucleic acids [36]. Similarly, polyphenols donate hydrogen atoms to neutralize ROS via creating water-soluble compounds [37], meaning high polyphenol content also increases stress tolerance.

$\mathrm{Na}^{+}$uptake in WT was higher than in transgenic plants, and consequently, WT also contained lower concentrations of essential nutrients (e.g., $\mathrm{K}^{+}, \mathrm{Ca}^{2+}, \mathrm{P}^{+}$, and $\left.\mathrm{Mg}^{2+}\right)$. This deficiency in essential nutrients likely disturbed normal physiological function and is thus a factor inhibiting plant growth. Our results support the findings of Abdallah et al. [38], who demonstrated that high $\mathrm{Na}^{+}$accumulation in Solanum nigrum affected essential nutrient uptake and reduced plant growth.

Antioxidant enzymes SOD, POX, and CAT are known to protect plants from oxidative damage during extreme stress conditions $[39,40]$. Additionally, SOD, CAT, and POD actively scavenge ROS in salt-stressed plants [41, 42]. Notably, enhanced anthocyanin production increases SOD, CAT, and POD activities, and improves the survival rate of Arabidopsis seedlings under salt stress [42]. In this study, we found that salt-stress tolerance is likely linked to differential antioxidant gene expression in the transgenic lines and WT. Specifically, we observed that salt-stress tolerance $\left(\mathrm{T}_{2}-\mathrm{S}>\mathrm{T}_{2}-\mathrm{R}>\mathrm{T}_{2^{-}}\right.$ $\mathrm{P}>\mathrm{WT}$ ) correlated well with $S O D, P O X$, and $C A T$ 


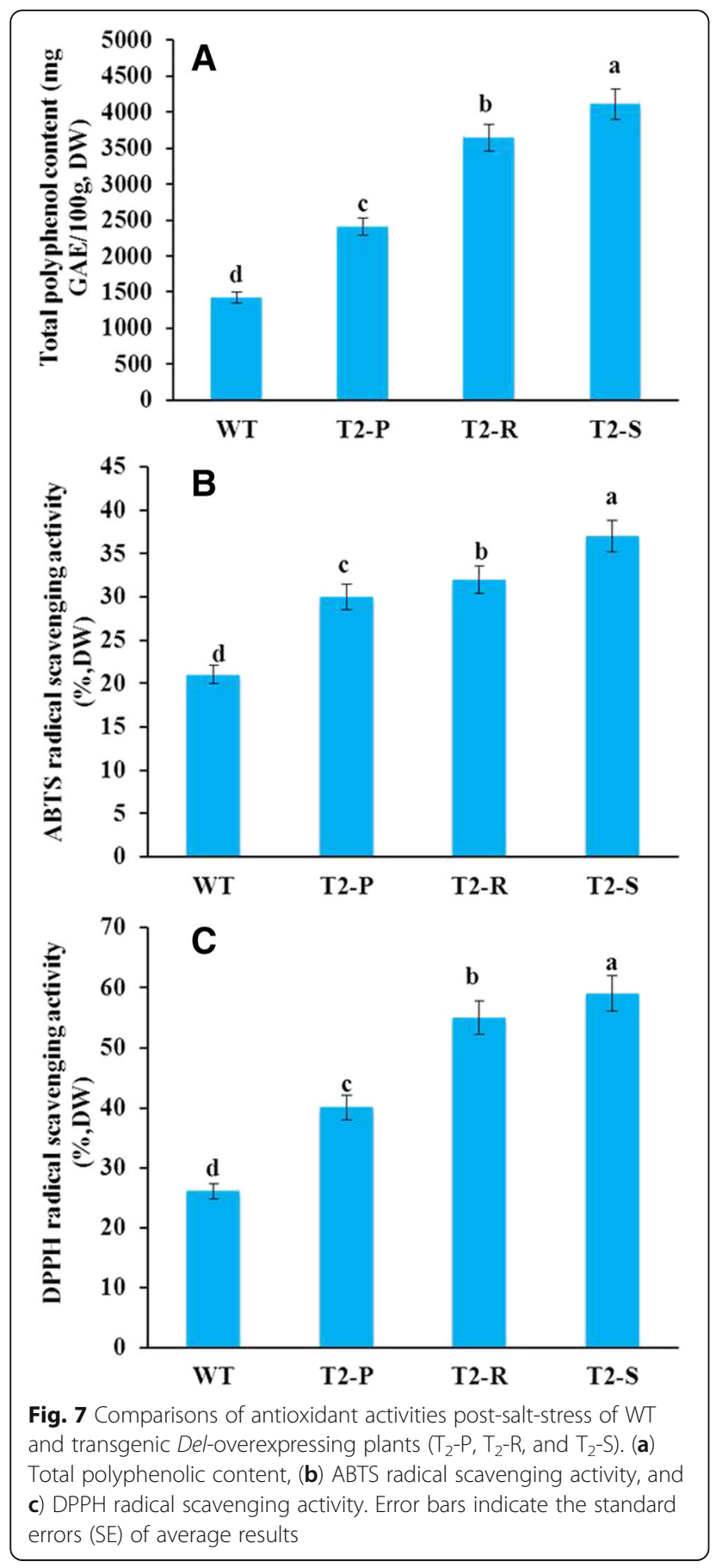

transcript levels. From the results, it seemed that overexpression of $\mathrm{Del}$ gene could enhance not only anthocyanin biosynthetic genes but also the antioxidant-related gene at transcript levels. Similarly, Wang et al. [34] also recently claimed that overexpression of $\mathrm{Del}$ gene could activate expression of the same genes. Many studies have also shown that overexpression of antioxidant genes heightens ROS scavenging activity and improves salt stress tolerance
[43]. Thus, the possible explanation for the stress tolerance could be due to anthocyanin accumulation as well as induction of antioxidant-related genes.

Furthermore, Goel et al. [44] documented that osmotin overexpression in several plant species raises proline content, thereby increasing salt-stress tolerance. In this study, osmotin transcript levels also correlated well with salt tolerance (again, $\mathrm{T}_{2}-\mathrm{S}>\mathrm{T}_{2}-\mathrm{R}>\mathrm{T}_{2}-\mathrm{P}>\mathrm{WT}$ ). Hence, our work here corroborates previous studies showing a direct association between osmotin transcript level and degree of salt tolerance

Recent studies reported that anthocyanin accumulation was directly associated with drought tolerance in several plant species $[19,20,31,32,34]$. Under drought stress, transgenic plants generally exhibited better plant growth than WT. Here, we noticed that drought tolerance varied depending on anthocyanin accumulation $\left(\mathrm{T}_{2}-\mathrm{S}>\mathrm{T}_{2}-\mathrm{R}>\mathrm{T}_{2}-\mathrm{P}>\mathrm{WT}\right)$, suggesting that the effect of $\mathrm{Del}$ overexpression in enhancing anthocyanin content and antioxidant activity also induces drought tolerance. Our conclusion is consistent with the findings of previous studies [19, 20, 31, 32, 34].

We observed here that anthocyanin-accumulating transgenic lines experienced a greater reduction in stomatal density than WT, consistent with previous studies $[45,46]$. The recent studies that implicated anthocyanins in drought tolerance $[19,20,31,32,34]$ did not examine any potential association between anthocyanin production and stomatal density reduction. Thus, our report is the first to link reduced stomatal density with anthocyanin production, providing a mechanism for increased drought tolerance in tobacco. On the other hand, reduction of the stomatal density could also be directly associated with overexpression of the bHLH transcription factor ( $\mathrm{Del}$ gene) because overexpression of a bHLH transcription factor (PebHLH35) from Populus euphratica was found to confer drought tolerance by reducing stomatal density [47].

As an antioxidant, anthocyanins can scavenge ROS into vacuoles under drought stress, making them osmoregulators that maintain water homeostasis in plants [20]. Here, it is likely that anthocyanin accumulation prevented water loss in whole transgenic plants. Thus, our results support the findings of Nakabayashi et al. [20]. In addition, one possible explanation for less reduction of water in the plants could also be due to direct influence of the bHLH transcription factor (Del gene) because overexpression of the bHLH transcription factor (PebHLH35) delayed water loss in Arabidopsis [47].

Leaf MDA concentration is frequently used as an indicator of drought stress in plants, supported by data showing a direct association between low MDA concentrations and drought tolerance $[34,48]$. In our work, MDA concentrations detected in Del-overexpressing transgenic lines had lower MDA concentrations than 

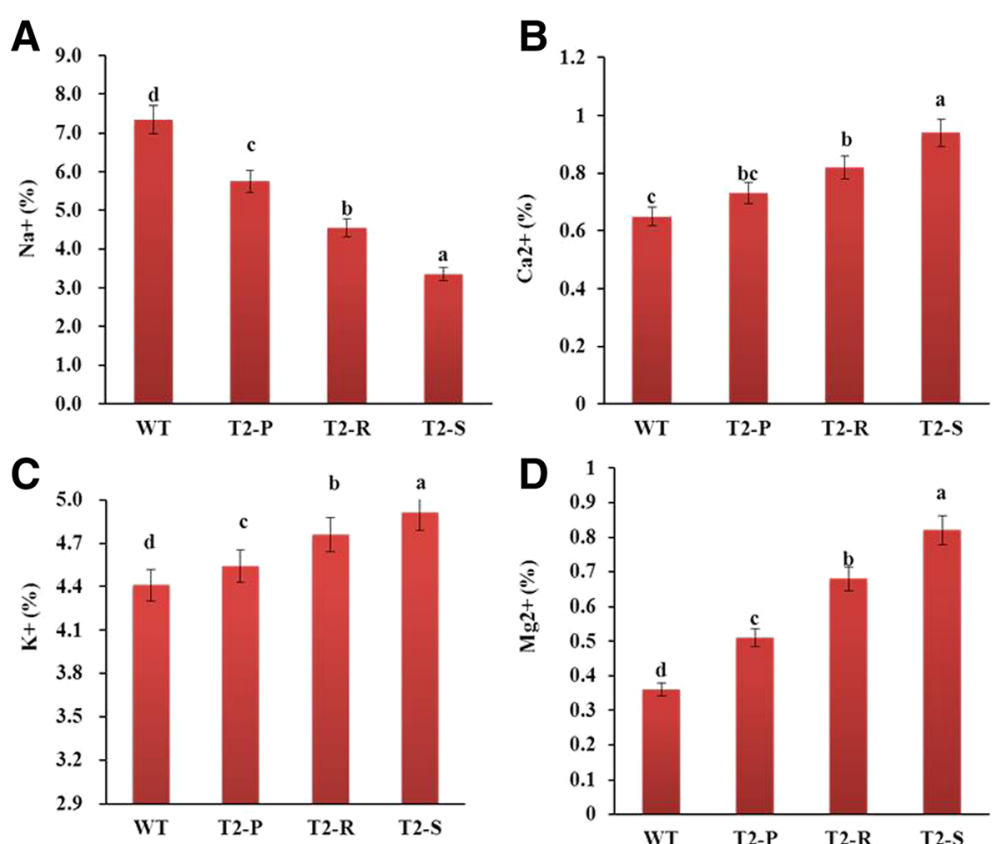

Fig. 8 lon content of leaf tissue following salt-stress treatment of WT and transgenic Del-overexpressing plants $\left(T_{2}-P, T_{2}-R\right.$, and $\left.T_{2}-S\right)$. (a) $N a^{+}$, (b) $\mathrm{Ca}^{2+},(\mathbf{c}) \mathrm{K}^{+}$, and $(\mathbf{d}) \mathrm{Mg}^{2+}$. Error bars indicate the standard errors (SE) of average results

WT, and-as already stated-transgenic lines were also more resistant to water deficit. Thus, our data are in line with existing evidence showing that plants with lower MDA concentrations are more drought-tolerant. Recently, Wang et al. [34] also claimed that overexpression of Del gene enhanced flavonoid levels and lowered MDA content in Arabidopsis. Moreover, increased anthocyanin content in the transgenic lines were also found to be likely associated with lower MDA concentration.

\section{Conclusion}

This study focuses on functional role of Snapdragon $\mathrm{Del}$ gene, a bHLH transcription factor, in anthocyanin production and abiotic stress tolerances for Nicotiana tabaccum cv. Xanthi. The results support that Del gene is able to enhance both anthocyanin production and the stress tolerance by regulating anthocyanin biosynthesis genes and antioxidant-related genes. Thus, we expect that $\mathrm{Del}$ gene could be exploited as a dual functional
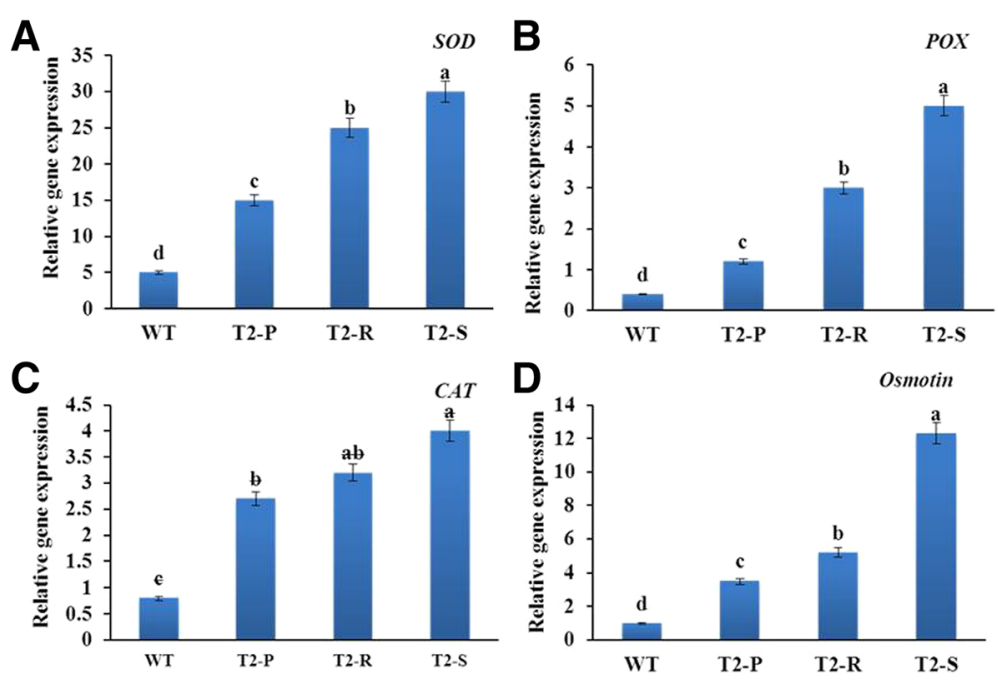

Fig. 9 Analysis of antioxidant-related gene expression following salt stress of WT and transgenic Del-overexpressing plants ( $T_{2}-P_{1} T_{2}-R$, and $\left.T_{2}-S\right)$. (a) SOD, (b) POX, (c) CAT, and (d) Osmotin. Error bars indicate the standard errors (SE) of average results 


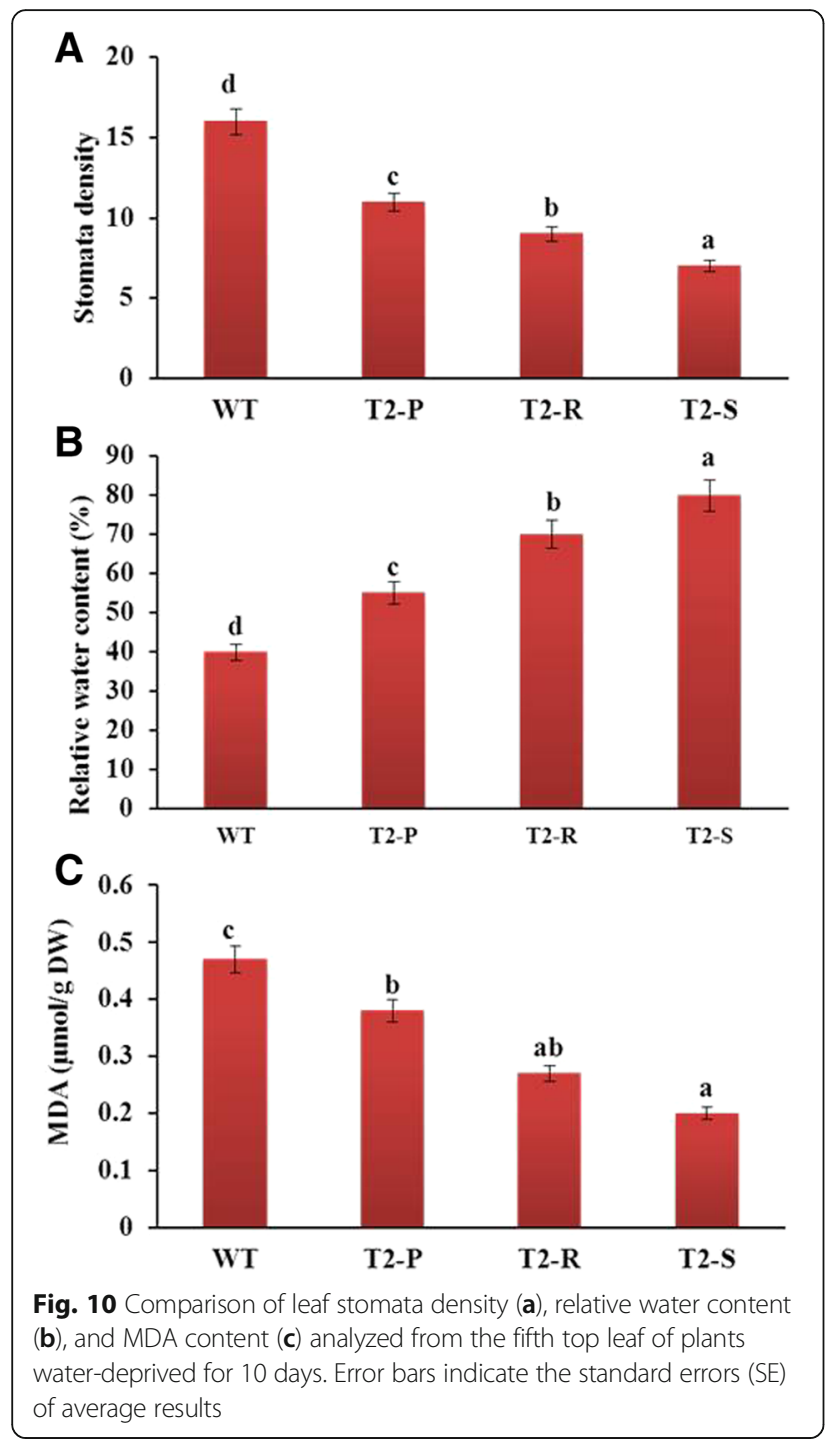

gene for improvement of anthocyanin production and the stress tolerances for horticultural crops.

\section{Methods}

Plant materials

Seven transgenic tobacco (cv. Xanthi, Japan Tobacco Co., Toyoda) lines were generated previously that expressed $\mathrm{Del}$ via the CaMV $35 \mathrm{~S}$ promoter [33]. The 35S-Del gene construct was provided by Professor Cathie Martin (John Innes Centre, UK). Three lines among the $\mathrm{T}_{0}$ plants displayed different anthocyaninaccumulation phenotypes: pale red, red, and strong red; these lines were selected and labeled as $T_{0}-P, T_{0}-R$, and $\mathrm{T}_{0}$-S, respectively (Fig. 1a).

\section{Generation of $T_{2}$ lines}

To generate $T_{1}$ plants, $T_{0}-P, T_{0}-R$, and $T_{0}-S$ plants were grown in a greenhouse (Fig. 1b) until flowering, and then self-pollinated. The resulting progenies were selected based on anthocyanin accumulation phenotype. Similarly, the final $T_{2}-P, T_{2}-R$, and $T_{2}-S$ plants used for further analysis were obtained through self-pollination of $\mathrm{T}_{1}$ plants, then subjected to the same phenotype screening process for anthocyanin accumulation.

\section{Analysis of total anthocyanin content}

Ten plants from the $T_{2}$ generation per line were selected for analysis of total anthocyanin content, following Ai et al. [49]. Briefly, $\sim 500 \mathrm{mg}$ ) of leaves per plant was grounded to a fine powder, which was transferred to an extraction solution for obtaining anthocyanins. The extract was incubated at $4{ }^{\circ} \mathrm{C}$ for $24 \mathrm{~h}$, then centrifuged at $13000 \mathrm{rpm}$ and $4{ }^{\circ} \mathrm{C}$ for $20 \mathrm{~min}$. The supernatant containing anthocyanin was analyzed with a spectrophotometer (Shimadzu, Kyoto, Japan). Error bars indicate the standard error (SE) of average anthocyanin content.

\section{RNA extraction and RT-PCR analysis}

To determine anthocyanin biosynthetic gene expression in $T_{2}-P, T_{2}-R$, and $T_{2}-S$ plants, total RNA was isolated

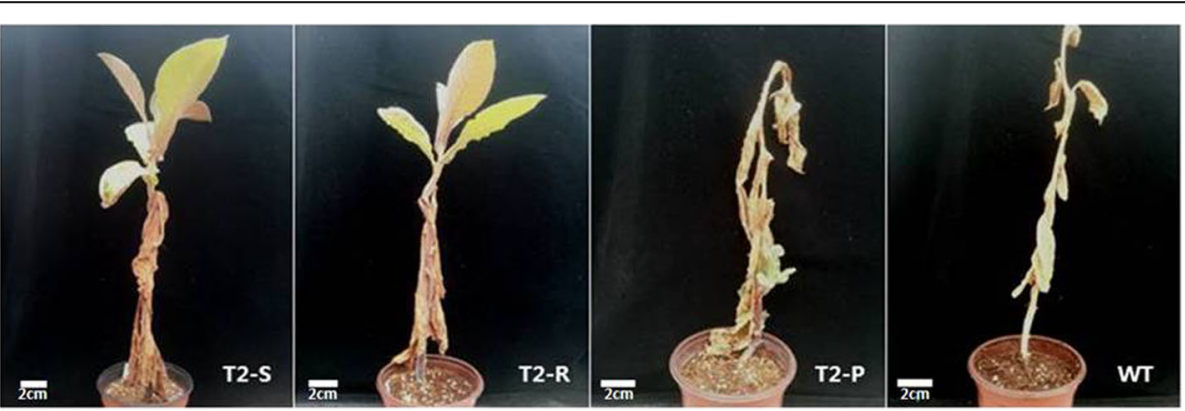

Fig. 11 Comparison of plant recovery following drought stress (photos taken 3 days after re-watering) in WT and transgenic Del-overexpressing plants $\left(T_{2}-P, T_{2}-R\right.$, and $\left.T_{2}-S\right)$ 
from $100 \mathrm{mg}$ of leaf tissue per line (transgenic + WT) using TRI Reagent ${ }^{\mathrm{TM}}$ Solution (Ambion, USA). The synthesis of cDNA was performed using Transcription Kit (Applied Biosystems, USA). Table 1 lists the primers and PCR conditions for amplification of NtCHI, NtCHS, $N t F 3 H, N t D F R$, and NtANS, as well as the reference $A C T I N$ gene.

\section{Transcriptional analysis of anthocyanin biosynthetic genes in vegetative and floral tissues using qRT-PCR}

Total RNA isolated from leaf and floral tissues of $\mathrm{T}_{2}$ plants were analyzed. Following manufacturer protocol, $1 \mu \mathrm{g}$ of total RNA and an oligo $\mathrm{dT}_{20}$ primer were used for reverse transcription (ReverTra Ace-á, Toyobo, Japan). Transcript levels of NtCHI, NtCHS, NtF3H, $N t D F R, N t A N S$, and ACTIN were measured using a StepOnePlus Real-Time PCR system (Thermo Fisher Scientific, Waltham, USA) (Ai et al. 2016). The primers and PCR conditions for the detected genes are listed in Table 1. Five samples per line were used, and the analysis was repeated three times.

\section{Environmental stress experiments Plant materials}

Seeds of $\mathrm{T}_{2}-\mathrm{P}, \mathrm{T}_{2}-\mathrm{R}, \mathrm{T}_{2}-\mathrm{R}$, and WT tobacco plants were germinated on separate seedling beds in a greenhouse with an average temperature of $25{ }^{\circ} \mathrm{C}$. Seedlings were allowed to grow for three weeks. Subsequently, uniform, healthy WT and transgenic plants with the appropriate anthocyanin phenotypes were transferred to individual

Table 1 Primer sequences for RT-PCR and qRT-PCR of anthocyanin biosynthetic genes

\begin{tabular}{|c|c|c|}
\hline Gene & Accession No. & Primer sequences \\
\hline \multirow[t]{2}{*}{ CHS } & AF311783 & F, 5'- TTGTTCGAGCTTGTCTCTGC -3' \\
\hline & & R, 5'- AGCCCAGGAACATCTTTGAG-3' \\
\hline \multirow[t]{2}{*}{$\mathrm{CHI}$} & AB213651 & F, 5'- GTCAGGCCATTGAAAAGCTC -3' \\
\hline & & R, 5'- CTAATCGTCAATGCCCCAAC - $3^{\prime}$ \\
\hline \multirow[t]{2}{*}{$\mathrm{F} 3 \mathrm{H}$} & AB289450 & F, 5'- CAAGGCATGTGTGGATATGG-3' \\
\hline & & R, 5'- TGTGTCGTTCAGTCCAAGG -3' \\
\hline \multirow[t]{2}{*}{ DFR } & AB289448 & F, 5'- AACCAACAGTCAGGGGAATG -3' \\
\hline & & R, 5'- TTGGACATCGACAGTTCCAG-3' \\
\hline \multirow[t]{2}{*}{ ANS } & AB289447 & F, 5'- TGGCGTTGAAGCTCATACTG -3' \\
\hline & & R, 5'- GGAATTAGGCACACACTITGC -3' \\
\hline \multirow[t]{2}{*}{ ACTIN } & AB158612 & F, 5'- GGTCATTACCATTGGCTCAGA -3' \\
\hline & & R, 5'- CAACAAGTGATGGCTGGAATAAA -3' \\
\hline
\end{tabular}

CHS chalcone synthase, $\mathrm{CHI}$ chalcone isomerase, $\mathrm{F} 3 \mathrm{H}$ flavanone-3-hydroxylase, DFR dihydroflavonol 4-reductase, ANS anthocyanidin synthase, ACTIN reference gene used for expression normalization

PCR conditions for RT-PCR: $95^{\circ} \mathrm{C}(2 \mathrm{~min}) \rightarrow\left[95^{\circ} \mathrm{C}(20 \mathrm{~s}) \rightarrow 57{ }^{\circ} \mathrm{C}(40 \mathrm{~s}) \rightarrow 72{ }^{\circ} \mathrm{C}\right.$ (30 s) $) \times 35$ cycles $\rightarrow 72{ }^{\circ} \mathrm{C}(5 \mathrm{~min}) \rightarrow 4{ }^{\circ} \mathrm{C}$

PCR conditions for qRT-PCR: $95^{\circ} \mathrm{C}(10 \mathrm{~min}) \rightarrow\left[95^{\circ} \mathrm{C}(30 \mathrm{~s}) \rightarrow 57{ }^{\circ} \mathrm{C}(25 \mathrm{~s}) \rightarrow\right.$

$\left.72{ }^{\circ} \mathrm{C}(35 \mathrm{~s})\right] \times 40$ cycles $\rightarrow 95^{\circ} \mathrm{C}(15 \mathrm{~s}) \rightarrow 57^{\circ} \mathrm{C}(30 \mathrm{~s}) \rightarrow 95^{\circ} \mathrm{C}(15 \mathrm{~s})$
Table 2 Primer sequences for qRT-PCR of antioxidant- and proline-related genes

\begin{tabular}{lll}
\hline Gene & Accession No. & Primer sequences \\
\hline SOD & EU342358 & F; 5'- GCCAGCTTTGAAGATGAACGA-3' \\
& & R; 5'- GCCTAATGCTCTTCCCACCAT-3' \\
CAT & U93244 & F; 5'- GATGACAAGATGCTTCAAACTCGTA-3' \\
& & R; 5'- CACTTGGAGCATTAGCAGGAA-3' \\
POX & D11396.1 & F; 5'- ACTGCTCCGTCACCCAAAAC-3' \\
& & R; 5'- GCCCTGGTCCTGCTTAAGTC-3' \\
Osmotin & X95308 & F; 5'- ACTATCGAGGTCCGAACAACTG-3' \\
& & R; 5'- GCATTGATCACCCAAGTTGG-3' \\
\hline
\end{tabular}

pots. Prior to performing stress treatments, DPPH and ABTS radical scavenging activity, as well as total polyphenol content, were determined for each line (5 plants per line) following the methods of Kim et al. [50] and Lim et al. [35].

\section{Salt stress}

Three-week-old $\mathrm{T}_{2}-\mathrm{P}, \mathrm{T}_{2}-\mathrm{R}, \mathrm{T}_{2}-\mathrm{S}$, and WT plants (20 per line) were grown for another week under normal conditions before being subjected to an irrigation treatment every six days with increasing $\mathrm{NaCl}$ concentrations (50, 100, 150, 200, 250, and $300 \mathrm{mM}$ ). Growth variables (plant height and fresh weight) were evaluated at the end of irrigation, and the experiment was repeated three times. Plants were maintained in a growth chamber set to $22{ }^{\circ} \mathrm{C}$ and $\sim 60 \%$ relative humidity with a $16-\mathrm{h}$ photoperiod.

\section{Radical scavenging activity assay}

Radical scavenging activity from five samples per line was measured before and after salt stress using DPPH and ABTS assays, repeated in triplicate, (following Kim et al. [50]; Lim et al. [35]).

\section{Determination of total polyphenol content}

Total polyphenolic content per line was determined before and after salt stress, following Dewanto et al. [51], five samples per line were used, and the analysis was repeated three times.

\section{Determination of major ion content}

Post-salt-stress treatment, $\mathrm{Na}^{+}, \mathrm{K}^{+}, \mathrm{Ca}^{2+}$, and $\mathrm{Mg}^{2+}$ were extracted from $1 \mathrm{~g}$ of dried leaf tissue per line using $0.5 \% \mathrm{HNO}_{3}$. Ion content was then assayed through ion conductivity, as described by Cataldi et al. [52]. Measurements were performed in five samples with three replicates. 
Table 3 PCR conditions for qRT-PCR of antioxidant- and proline-related genes

\begin{tabular}{|c|c|}
\hline Genes & PCR conditions: \\
\hline SOD & $95^{\circ} \mathrm{C}(10 \mathrm{~min}) \rightarrow\left[95^{\circ} \mathrm{C}(30 \mathrm{~s}) \rightarrow 59^{\circ} \mathrm{C}(30 \mathrm{~s})\right] \times 40$ cycles $\rightarrow 95^{\circ} \mathrm{C}(15 \mathrm{~s}) \rightarrow 59^{\circ} \mathrm{C}(30 \mathrm{~s}) \rightarrow 95^{\circ} \mathrm{C}(15 \mathrm{~s})$ \\
\hline CAT & $95^{\circ} \mathrm{C}(10 \mathrm{~min}) \rightarrow\left[95^{\circ} \mathrm{C}(30 \mathrm{~s}) \rightarrow 59^{\circ} \mathrm{C}(30 \mathrm{~s})\right] \times 40$ cycles $\rightarrow 95^{\circ} \mathrm{C}(15 \mathrm{~s}) \rightarrow 59^{\circ} \mathrm{C}(30 \mathrm{~s}) \rightarrow 95^{\circ} \mathrm{C}(15 \mathrm{~s})$ \\
\hline POX & $95^{\circ} \mathrm{C}(10 \mathrm{~min}) \rightarrow\left[95^{\circ} \mathrm{C}(30 \mathrm{~s}) \rightarrow 60^{\circ} \mathrm{C}(30 \mathrm{~s})\right] \times 40$ cycles $\rightarrow 95^{\circ} \mathrm{C}(15 \mathrm{~s}) \rightarrow 60^{\circ} \mathrm{C}(30 \mathrm{~s}) \rightarrow 95^{\circ} \mathrm{C}(15 \mathrm{~s})$ \\
\hline Osmotin & $95^{\circ} \mathrm{C}(10 \mathrm{~min}) \rightarrow\left[95^{\circ} \mathrm{C}(30 \mathrm{~s}) \rightarrow 59^{\circ} \mathrm{C}(30 \mathrm{~s})\right] \times 40$ cycles $\rightarrow 95^{\circ} \mathrm{C}(15 \mathrm{~s}) \rightarrow 59^{\circ} \mathrm{C}(30 \mathrm{~s}) \rightarrow 95^{\circ} \mathrm{C}(15 \mathrm{~s})$ \\
\hline
\end{tabular}

\section{RNA extraction and analysis of gene expression by qRT- PCR}

To determine NtSOD, NtCAT, NtPOX, and NtOsmotin expression levels, qRT-PCR analysis was performed. Leaf tissue per line was sampled following salt-stress treatment. Total RNA extraction and analysis of gene expression by qRT-PCR were performed as described under "RNA extraction and RT-PCR analysis," as well as "Transcriptional analysis of anthocyanin biosynthetic genes in vegetative and floral tissues using qRT-PCR." ACTIN was used as an internal reference gene. Tables 2 and 3 list the primers and PCR conditions, respectively. Analysis was performed in five samples with three replicates.

\section{Drought stress}

Three-week-old $\mathrm{T}_{2}-\mathrm{P}, \mathrm{T}_{2}-\mathrm{R}, \mathrm{T}_{2}-\mathrm{S}$, and WT plants (20 per line) were grown for another week under well-watered conditions before a three-week water deprivation. Subsequently, normal watering conditions were reinstated for 3 days. Growth responses of the plants to drought stress and re-watering were evaluated, and the experiment was repeated three times.

\section{Determination of relative water content (RWC)}

Post-drought-stress RWC was determined using the fifth leaf from the top of plants subjected to 10 days of water deprivation. Leaves were excised and fresh leaf weight was immediately recorded. Leaves were then floated in deionized water at $4{ }^{\circ} \mathrm{C}$ overnight before recording their rehydrated weights. Finally, leaves were oven-dried at $70{ }^{\circ} \mathrm{C}$ overnight, and dry leaf weight was recorded. The formula for determining RWC is as follows: RWC $=$ (fresh weight - dry weight) / (rehydrated weight - dry weight). Five leaves per line were used to determine RWC, and the analysis was repeated three times.

\section{Analysis of stomatal density}

Leaf stomatal density was analyzed in the fifth leaf from the top of plants water-deprived for 10 days. Stomatal density was counted following method of Chung et al. [53]. Five leaves per line were used, and the analysis was repeated three times..

\section{Determination of malondialdehyde (MDA) content}

Malondialdehyde content was determined in the fifth leaf from the top of plants water-deprived for 10 days, following method of Bates et al. [54]. Five leaves per line were used, and the analysis was repeated three times.

\section{Statistical analysis}

Data were statistically analyzed in SPSS version 11.09 (IBM Corporation, Armonk, USA) and are presented as means \pm standard errors (SE). Duncan's multiple range test (DMRT) was used to separate the means, and significance was set at $\mathrm{P}<0.05$.

\section{Abbreviations \\ ABTS: 2, 2'-azino-bis-3-ethylbenzthiazoline-6-sulphonic acid; ANS: Anthocyanidin synthase; APX: Ascorbate peroxidase; bHLH: Basic helix-loop-helix; $\mathrm{Ca}^{2+}$ : Calcium ion; CAT: Catalase; $\mathrm{CH}$ : Chalcone isomerase; CHS: Chalcone synthase; Del: Delila; DFR: Dihydroflavonol 4-Reductase; DPPH: 1, 1-diphenyl-2-picrylhydrazyl radical; F3H: Flavanone-3-Hydroxylase; $\mathrm{K}^{+}$: Potassium ion; MDA: Malondialdehyde; $\mathrm{Mg}^{2}$ \\ ${ }^{+}$: Magnesium ion; $\mathrm{Na}^{+}$: Sodium ion; POX: Peroxidase; qRT-PCR: Quantitative real time polymerase chain reaction; ROS: Reactive oxygen species; RWC: Relative water content; SOD: Superoxide dismutase.}

\section{Acknowledgement \\ We wish to thank Professor Cathie Martin (Jonne Inn Centre, UK) for providing the plasmid.}

\section{Funding}

This work was supported by the Korea Institute of Planning and Evaluation for Technology in Food, Agriculture, Forestry and Fisheries (IPET) through the Agri-Bio industry Technology Development Program, funded by the Ministry of Agriculture, Food and Rural Affairs (MAFRA) (grant \#: 315002-5).

\section{Availability of data and materials}

The datasets used and/or analyzed during the current study are available from the corresponding authors on reasonable request

\section{Authors' contributions}

AHN designed the study, conducted the experiment, and wrote the manuscript. KIP, KBL, and CKK supervised experiments at all stages and performed critical revisions of the manuscript. TNA, YWK, JSH, and MYC assisted with experimental procedures and data analysis. All authors read and approved the final manuscript.

\section{Competing interests}

The authors declare that they have no competing interests.

Consent for publication

Not applicable.

Ethics approval and consent to participate

Nicotiana tabacum 'Xanthi' is widely used as model plant in plant biotechnology research. This research was conducted in accordance with the regulations of the Korean Government. 


\section{Deposition of data}

Not applicable.

\section{Publisher's Note}

Springer Nature remains neutral with regard to jurisdictional claims in published maps and institutional affiliations.

\section{Author details}

'Department of Horticultural Science, Kyungpook National University, Daegu 4165122, South Korea. ${ }^{2}$ Department of Horticulture \& Life Science, Yeungnam University, Gyeongsan 712-749, South Korea. ${ }^{3}$ Department of Agricultural Education, Sunchon National University, Suncheon, South Korea.

\section{Received: 15 December 2016 Accepted: 17 March 2017} Published online: 23 March 2017

\section{References}

1. Nishihara M, Nakatsuka T, et al. Genetic engineering of flavonoid pigments to modify flower color in floricultural plants. Biotechnol Lett. 2011:33:433-41.

2. Butelli E, Titta L, Giorgio M, Mock HP, Matros A, Peterek S, Schijlen EG, Hall RD, Bovy AG, Luo J, Martin C, et al. Enrichment of tomato fruit with healthpromoting anthocyanins by expression of select transcription factors. Nat Biotechnol. 2008:26:1301-8.

3. Maligeppagol M, Chandra GS, Navale PM, Deepa H, Rajeev PR, Asokan R, Babu KP, Barbu CSB, Rao VK, Kumar NKK, et al. Anthocyanin enrichment of tomato (Solanum lycopersicumL.) fruit by metabolic engineering. Curr Sci. 2013;105:72-80

4. Zhang Y, Butelli E, Alseekh S, Tohge T, Rallapalli G, Luo J, et al. Multi-level engineering facilitates the production of phenylpropanoid compounds in tomato. Nat Commun. 2015:6:1-11.

5. Mooney M, Desnos T, Harrison K, Jones, Carpenter R, Coen E, et al. Altered regulation of tomato and tobacco pigmentation genes caused by the delila gene of Antirrhinum. Plant J. 1995;7:333-9.

6. Farooq M, Wahid A, Kobayashi N, Fujita D, Basra SMA, et al. Plant drought stress: Effects, mechanisms and management. Agron Sustain Dev. 2009;29:185-212.

7. Flowers TJ, Yeo AR, et al. Breeding for salinity resistance in crop plants—where next? Aust J Plant Physiol. 1995;22:875-84.

8. Hakim MA, Juraimi AS, Hanafi MM, et al. Biochemical and anatomical changes and yield reduction in rice (Oryza sativa L.) under varied salinity regimes. Biomed Res Int. 2014;11:208584.

9. Miller G, Suzuki N, Ciftci-Yilmaz S, Mittler R, et al. Reactive oxygen species homeostasis and signalling during drought and salinity stresses. Plant Cell Environ. 2010;33:453-67.

10. Winkel-Shirley B, et al. Biosynthesis of flavonoids and effects of stress. Curr Opin Plant Biol. 2002;5:218-23.

11. Dixon RA, Xie DY, Sharma SB, et al. Proanthocyanidins: a final frontier in flavonoid research? New Phytol. 2005;165:9-28.

12. Bors W, Michel C, Saran M, et al. Flavonoid antioxidants: rate constants for reactions with oxygen radicals. Methods Enzymol. 1994;234:420-9.

13. Yamasaki $H$, Uefuji $H$, Sakihama $Y$, et al. Bleaching of the red anthocyanin induced by superoxide radical. Arch Biochem Biophys. 1996;332:183-18.

14. Meng X, Yin B, Feng HL, Zhang S, Liang XQ, Meng QW, et al. Over-expression of R2R3-MYB gene leads to accumulation of anthocyanin and enhanced resistance to chilling and oxidative stress. Biol Plant. 2014:58:121-30.

15. Xie YJ, Ling TF, Han Y, Liu K, Zheng Q, Huang L, Yuan X, He Z, Hu B, Fang L, Shen $Z$, Yang $Q$, Shen W, et al. Carbon monoxide enhances salt tolerance by nitric oxide-mediated maintenance of ion homeostasis and upregulation of antioxidant defence in wheat seedling roots. Plant Cell Environ. 2008;31:1864-81.

16. Agati G, Biricolti S, Guidi L, Ferrini F, Fini A, Tattini M, et al. The biosynthesis of flavonoids is enhanced similarly by UV radiation and root zone salinity in L. vulgare leaves. J Plant Physiol. 2011;168:204-12.

17. Cheng YJ, Kim MD, Deng XP, Kwak SS, Chen W, et al. Enhanced salt stress tolerance in transgenic potato plants expressing IbMYB1, a sweet potato transcription factor. J Microbiol Biotechnol. 2013:23:1737-46.

18. Dehghan S, Sadeghi M, Pöppel A, Fischer R, Lakes-Harlan R, Kavousi HR, Vilcinskas A, Rahnamaeian M, et al. Differential inductions of phenylalanine ammonia-lyase and chalcone synthase during wounding, salicylic acid treatment, and salinity stress in safflower, Carthamus tinctorius. Biosci Rep. 2014;34:273-82.
19. Fini A, Brunetti C, Di Ferdinando M, Ferrini F, Tattini M, et al. Stress-induced flavonoid biosynthesis and the antioxidant machinery of plants. Plant Signal Behav. 2011;6:709-11.

20. Nakabayashi R, Yonekura-Sakakibara K, Urano K, Suzuki M, Yamada Y, Nishizawa T, Matsuda F, Kojima M, Sakakibara H, Shinozaki K, et al. Enhancement of oxidative and drought tolerance in Arabidopsis by overaccumulation of antioxidant flavonoids. Plant J. 2014;77:367-79.

21. Huang ZA, Zhao T, Fan HJ, Wang N, Zheng SS, Ling HQ, et al. The upregulation of NtAN2 expression at low temperature is required for anthocyanin accumulation in juvenile leaves of $L c$-transgenic Tobacco (Nicotiana tabacum L.). J Genet Genomics. 2012;39:149-56.

22. Nakatsuka T, Abe Y, Kakizaki Y, Yamamura S, Nishihara M, et al. Production of red-flowered plants by genetic engineering of multiple flavonoid biosynthetic genes. Plant Cell Rep. 2007;26:1951-9.

23. Geekiyanage S, Takase T, Ogura Y, Kiyosue, et al. Anthocyanin production by over-expression of grape transcription factor gene VImybA2 in transgenic tobacco and Arabidopsis. Plant Biotechnol Rep. 2007;1:11-48.

24. Lim SH, Sohn SH, Kim DH, Kim JK, Lee JY, Kim YM, Ha SH, et al. Use of an anthocyanin production phenotype as a visible selection marker system in transgenic tobacco plant. Plant Biotechnol Rep. 2012;6:203-11.

25. Han Y, Vimolmangkang S, Soria-Guerra RE, Korban SS, et al. Introduction of apple ANR genes into tobacco inhibits expression of both CHI and DFR genes in flowers, leading to loss of anthocyanin. J Exp Bot. 2012;63:2437-47.

26. Agati G, Azzarello E, Pollastri S, Tattini M, et al. Flavonoids as antioxidants in plants: location and functional significance. Plant Sci. 2012;196:67-76.

27. Oh JE, Kim YH, Kim JH, Kwon YR, Lee $H$, et al. Enhanced level of anthocyanin leads to increased salt tolerance in Arabidopsis PAP1-D plants upon sucrose treatment. J Korean Soc Appl Biol. 2011;1:79-88.

28. Hossain MA, Kim S, Kim KH, Lee SJ, Lee H, et al. Flavonoid compounds are enriched in lemon balm (Melissa officinalis) leaves by a high level of sucrose and confer increased antioxidant activity. Hortscience. 2009;44:1907-13.

29. Lijuan C, Huiming G, Yi L, Hongmei C, et al. Chalcone synthase EaCHS1 from Eupatorium adenophorum functions in salt stress tolerance in tobacco. Plant Cell Rep. 2015;34:885-94.

30. Qi L, Yang J, Yuan Y, Huang L, Chen P, et al. Overexpression of two R2R3MYB genes from Scutellaria baicalensis induces phenylpropanoid accumulation and enhances oxidative stress resistance in transgenic tobacco. Plant Physiol Biochem. 2015;94:235-43.

31. Yuan Y, Qi L, Yang J, Wu C, Liu Y, Huang L, et al. A Scutellaria baicalensis R2R3-MYB gene, SbMYB8, regulates flavonoid biosynthesis and improves drought stress tolerance in transgenic tobacco. Plant Cell Tiss Organ Cult. 2015;120:961-72.

32. Wang F, Zhu H, Chen D, Li Z, Peng R, Yao Q, et al. A grape bHLH transcription factor gene, $\mathrm{VvbHLH}$, increases the accumulation of flavonoids and enhances salt and drought tolerance in transgenic Arabidopsis thaliana. Plant Cell Tiss Organ Cult. 2016;125:387-98.

33. Naing $\mathrm{AH}$, Lim KB, Kim CK, et al. The usage of snapdragon Delila (Del) gene as a visible selection marker for the antibiotic-free transformation system. J Plant Biol. 2015:58:110-6.

34. Wang F, Zhu H, Kong W, Peng R, Liu Q, et al. The Antirrhinum AmDEL gene enhances flavonoids accumulation and salt and drought tolerance in transgenic Arabidopsis. Planta. 2016;244:59-73.

35. Lim SH, Song JH, Kim DH, Kim JK, Lee JY, Kim YM, Ha SH, et al. Activation of anthocyanin biosynthesis by expression of the radish R2R3-MYB transcription factor gene RsMYB1. Plant Cell Rep. 2016;35:641-53.

36. Halliwell B, Gutteridge JMC, et al. Free Radicals in Biology and Medicine. Oxford: Claredon Press; 1985.

37. Sakihama Y, Cohen MF, Grace SC, Yamasaki H, et al. Plant phenolic antioxidant and prooxidant activities: phenolics-induced oxidative damage mediated by metals in plants. Toxicology. 2002;177:67-70.

38. Abdallah SB, Aung B, Amyot L, Lalin I, Lachâal M, Karray-Bouraoui N, et al. Salt stress $(\mathrm{NaCl})$ affects plant growth and branch pathways of carotenoid and flavonoid biosyntheses in Solanum nigrum. Acta Physiol Plant. 2016;38:1-13.

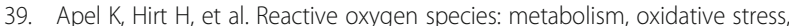
and signal transduction. Annu Rev Plant Biol. 2004;55:373-99.

40. Frary A, Göl D, Keleş D, Okmen B, Pinar H, Siğva HO, Yemenicioğlu A, Doğanlar S, et al. Salt tolerance in Solanum pennellii : antioxidant response and related OTL. BMC Plant Biol. 2010:10:58-74.

41. Li JT, Qiu ZB, Zhang XW, Wang LS, et al. Exogenous hydrogen peroxide can enhance tolerance of wheat seedlings to salt stress. Acta Physiol Plant. 2011;33:835-42 
42. Qiu ZB, Wang YF, Zhu AJ, Peng FL, Wang LS, et al. Exogenous sucrose can enhance tolerance of Arabidopsis thaliana seedlings to salt stress. Biol Plant. 2014;58:611-7

43. Roxas VP, Lodhi SA, Garret DK, Mahan JR, Allen RD, et al. Stress tolerance in transgenic tobacco seedlings that overexpress glutathione s-transferase/ glutathione peroxidase. Plant Cell Physiol. 2000;41:1229-34.

44. Goel D, Singh AK, Yadav V, Babbar SB, Bansal KC, et al. Overexpression of osmotin gene confers tolerance to salt and drought stresses in transgenic tomato (Solanum lycopersicumL.). Protoplasma. 2010;245:133-41.

45. Wang J, Sun PP, Chen CL, Wang Y, Fu XZ, Liu JH, et al. An arginine decarboxylase gene PtADC from Poncirus trifoliata confers abiotic stress tolerance and promotes primary root growth in Arabidopsis. J Exp Bot. 2011;62:2899-914

46. Xie C, Zhang R, Qu Y, Miao Z, Zhang Y, Shen X, Wang T, Dong J, et al. Overexpression of MtCAS31 enhances drought tolerance in transgenic Arabidopsis by reducing stomatal density. New Phytol. 2012;195:124-35.

47. Dong Y, Wang C, Han X, Tang S, Liu S, Xia X, Yin W, et al. A novel bHLH transcription factor PebHLH35 from Populus euphratica confers drought tolerance through regulating stomatal development, photosynthesis and growth in Arabidopsis. Biochem Biophys Res Commun. 2014;450:453-8.

48. Esfandiari EO, Shakiba MR, Mahboob SA, et al. Water stress, antioxidant enzyme activity and lipid peroxidation in wheat seedling. J Food Agric Environ. 2007:5:149-53

49. Ai TN, Naing AH, Arun M, Kim CK, et al. Sucrose-induced anthocyanin accumulation in vegetative tissue of Petunia plants regures anthocyanin regulatory transcription factor genes. Plant Sci. 2016;252:144-50.

50. Kim GR, Jung ES, Lee $\mathrm{S}$, Lim SH, Ha SH, Lee CH, et al. Combined mass spectrometry-based metabolite profiling of different pigmented rice (Oryza sativa L.) seeds and correlation with antioxidant activities. Molecules. 2014;19:15673-86.

51. Dewanto $\mathrm{V}, \mathrm{Wu}$ X, Adom KK, Liu RH, et al. Thermal processing enhances the nutritional value of tomatoes by increasing total antioxidant activity. J Agric Food Chem. 2002:50:3010-4.

52. Cataldi TRI, Margiotta G, Del Fiore A, Bufo SA, et al. lonic content in plant extracts determined by ion chromatography with conductivity detection. Phytochem Anal. 2003;14:176-83.

53. Chung MY, Kim CY, Min JS, Lee DJ, Naing AH, Chung JD, Kim CK, et al. In vitro induction of tetraploids in an interspecific hybrid of calanthe (Calanthe discolor $\times$ Calanthe sieboldii) through colchicine and oryzalin treatments. Plant Biotechnol Rep. 2014;8:251-7.

54. Bates LS, Waldren RP, Tear ID, et al. Rapid determination of free proline for water-stress studies. Plant Soil. 1973:39:205-7.

\section{Submit your next manuscript to BioMed Central and we will help you at every step:}

- We accept pre-submission inquiries

- Our selector tool helps you to find the most relevant journal

- We provide round the clock customer support

- Convenient online submission

- Thorough peer review

- Inclusion in PubMed and all major indexing services

- Maximum visibility for your research

Submit your manuscript at www.biomedcentral.com/submit 